\title{
Influence of the counter anion and steric hindrance of pyrazolyl and imidazolyl flexible ligands on the structure of zinc-based coordination polymers.
}

Valiollah Nobakht ${ }^{\mathrm{a}}$, Azizolla Beheshti ${ }^{\mathrm{a}, *}$, Davide M. Proserpio ${ }^{\mathrm{b}, \mathrm{c}, *}$, Lucia Carlucci $^{\mathrm{b}}$, Carmel T. Abrahams ${ }^{\mathrm{d}}$

${ }^{a}$ Department of Chemistry, Faculty of Sciences, Shahid Chamran University, Ahvaz, Iran. Fax: +98 611 3321042,E-mail: beheshti_a@hotmail.com

${ }^{b}$ Dipartimento di Chimica, Università degli Studi di Milano, Via C. Golgi 19, 20133, Milano, Italy. Fax: +390250314454, E-mail: davide.proserpio@unimi.it

${ }^{c}$ Samara Center for Theoretical Materials Science (SCTMS) Samara State University, Samara 443011, Russia

${ }^{d}$ Department of Chemistry, La Trobe University, Bundoora 3086, Victoria, Australia. 


\begin{abstract}
Treatments of flexible 1,4-bis(3,5-dimethylpyrazolyl)butane (bbd), 1,4-bis(imidazolyl)butane (bib) and 1,4-bis(2-methylimidazolyl)butane (bmib) ligands with zinc salts at room temperature, resulted in the formation of four novel metal-organic coordination architectures: $\left[\mathrm{ZnI}_{2}(\mu-\mathrm{bbd})\right]_{\mathrm{n}}(\mathbf{1}),\left[\mathrm{Zn}(\mathrm{NCS})_{2}(\mu-\mathrm{bbd})\right]_{\mathrm{n}}(2),\left\{\left[\mathrm{Zn}(\mu-\mathrm{bib})_{2}\right]\left(\mathrm{ClO}_{4}\right)_{2} \cdot\left(\mathrm{Et}_{2} \mathrm{O}\right)_{0.5} \cdot\left(\mathrm{H}_{2} \mathrm{O}\right)_{0.25}\right\}_{\mathrm{n}}(\mathbf{3})$ and $\left\{\left[\mathrm{Zn}(\mu-\mathrm{bmib})_{2}\right]\left(\mathrm{ClO}_{4}\right)_{2} \cdot\left(\mathrm{H}_{2} \mathrm{O}\right)_{4}\right\}_{\mathrm{n}}(4)$. X-ray crystallographic analyses show different $1 \mathrm{D}$ and 3D polymeric structures for compounds 1-4 due to the variation of the counter anions, solvent, steric hindrance and position of donating atoms in the structure of flexible ligands. In 1 and 2, one-dimensional (1D) zig-zag polymeric chains are formed via metal centers and $\mu$ bbd ligands.Complex 3 shows a 3-fold interpenetrated 3D architecture with $10^{3}$-ths network topology. In contrast to $\mathbf{3}$, in the structure of $\mathbf{4}$ neighboring $\mathrm{Zn}$ (II) ions are interconnected by a double-bridging $\mu$-bmib ligands to form an infinite 1D polymeric double chain. The conformations of the flexible ligands were analyzed in detail.
\end{abstract}

Keywords: Zinc, Coordination polymer, Flexible ligand, Counter anion effect, Pyrazolyl and imidazolyl ligand 


\section{Introduction}

The past decade has seen an explosive growth in preparation, characterization, and study of materials known as coordination polymers or metal-organic frameworks (MOFs). These materials are constructed by self-assembly of transition metal ions or metal-containing clusters, known as secondary building units (SBUs), and organic bridging ligands through strong coordination bonds obtaining 1D to 3D networks. By varying the SBUs and organic linkers thousands of MOFs with fascinating structures and interesting properties have been prepared and studied [1]. The construction of MOFs remains a popular area due to their potential applications in various fields such as separation[2], gas storage[3], ion exchange[4], magnetism[5], luminescence[6], sensing[7], drug delivery[8] and catalysis[9].Generally, the chemical structures of these materials are influenced by many factors, such as crystallization solvent, the nature of the counter anion, the preferred coordination environment of the metal center and the location and orientation of donor atoms in a polydentate ligand. The ability of such ligands to participate in non-covalent bonds, such as hydrogen-bonding and $\pi \cdots \pi$ stacking interactions have also a significant structure-directing influence. Factors such as steric hindrance, flexibility and spacer length of the ligands and the metal/ligand ratio also play important roles in the generation of novel coordination polymers [10]. The $\mathrm{sp}^{3}$ hybridization of $-\mathrm{CH}_{2}$ - spacers allow flexible ligands to bend and rotate freely when coordinate to metal centers, generating different conformations and making possible the formation of a variety of architectures and topologies. In recent years, there is an increasing interest in coordination architectures built by flexible bis(imidazolyl)[11] and bis(pyrazolyl)based [10a-c,12] bridging ligands due to the fact that the five-membered aromatic Nheterocycles, including imidazole- and pyrazole-derivatives, are known to function as ligands in compounds which are widely used in medicine, agriculture, industry and coordination chemistry. Imidazolate is also an important ligand in many metalloenzymes, such as copper/zinc superoxide dismutases [13].

In order to extend our work on the synthesis and structural characterizations of novel topological frameworks and investigate the influence of the reaction condition and solvent system, as well as the effect of steric hindrance of the imidazole and pyrazole ring substituents of the flexible ligands on the structure of complexes, the syntheses, crystal structures and thermal stabilities of four new zinc-based coordination polymers containing 
flexible bidentate nitrogen donor ligands (scheme 1) are reported here.

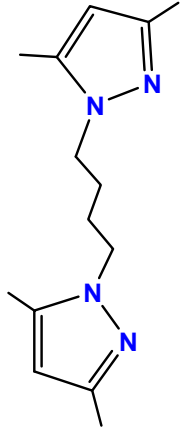

bbd

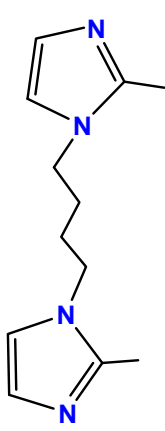

bmib

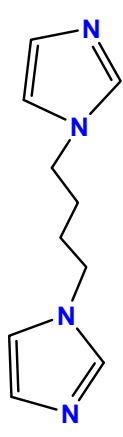

bib

Scheme 1: Structures of the ligands used in this work.

\section{Experimental Section}

\section{1. Materials and Physical Measurements}

All experiments were carried out in air. The starting materials were purchased from commercial sources and used without further purification; bbd [12a], bib [11f] and bmib [14] were prepared from them by published methods. The infrared spectra $\left(4000-400 \mathrm{~cm}^{-1}\right)$ were recorded from $\mathrm{KBr}$ discs with a BOMEN MB102 FT-IR spectrometer. The elemental analyses for $\mathrm{C}, \mathrm{H}$ and $\mathrm{N}$ were performed on a Costech-ECS $4010 \mathrm{CHNSO}$ analyzer. Thermal analysis was performed on a Bahr-STA 503 TG/DTA or on a Perkin-Elmer Diamond TG/DTA thermal analyzers under dynamic nitrogen. A ramp rate of $10{ }^{\circ} \mathrm{C} \cdot \mathrm{min}^{-1}$ in the range of $50-800^{\circ} \mathrm{C}$ was used.

\subsection{Preparation of the coordination polymers}

\section{2. 1. Synthesis of $\left[\mathrm{ZnI}_{2}(\mu-b b d)\right]_{n}(1)$.}

bbd $(0.13 \mathrm{~g}, 0.53 \mathrm{mmol})$ was added to a solution of $\mathrm{ZnI}_{2}(0.17 \mathrm{~g}, 0.53 \mathrm{mmol})$ in $\mathrm{CH}_{3} \mathrm{OH}(40$ $\mathrm{mL}$ ) and the reaction mixture was stirred at room temperature overnight. The resulting colorless solution was filtered and the clear filtrate was concentrated under reduced pressure to ca. $20 \mathrm{~mL}$. Colorless air-stable single crystals of $\mathbf{1}$ were obtained by leaving the saturated solution of 1 to stand in a refrigerator for 3-4 days. The crystals were washed with diethyl ether and dried in vacuum. (0.21g, 68\% yield based on $\mathrm{Zn})$. Anal. Calcd for $\mathrm{C}_{14} \mathrm{H}_{22} \mathrm{I}_{2} \mathrm{~N}_{4} \mathrm{Zn}$ : C 29.7, H 3.9, N 9.9; Found: C 30.1, H 3.8, N 9.7. FT-IR $\left(\mathrm{cm}^{-1}\right)$ : 491(w), 701(w), 738(w), 797(s), 808(s), 920(w), 1009(m), 1046(s), 1112(m), 1230(w), 1272(m), 1324(m), 1376(s), 1421(s), 1466(s), 1551(vs), 2866(w), 2934(m) 3121(w). 


\section{2. 2. Synthesis of $\left[\mathrm{Zn}(\mathrm{NCS})_{2}(\mu-b b d)\right]_{n}(2)$.}

$\mathrm{ZnCl}_{2}(0.2 \mathrm{~g}, 1.46 \mathrm{mmol})$ was added to a solution of $\mathrm{KSCN}(0.28 \mathrm{~g}, 2.9 \mathrm{mmol})$ in $\mathrm{CH}_{3} \mathrm{CN}$ or $\mathrm{CH}_{3} \mathrm{OH}(40 \mathrm{~mL})$ and the reaction mixture was stirred for $0.5 \mathrm{~h}$ at room temperature. bbd $(0.36 \mathrm{~g}, 1.46 \mathrm{mmol})$ was added to the resulting solution and the reaction mixture was stirred at room temperature overnight. The colorless mixture was then filtered to remove small amount of white precipitate. Colorless air-stable single crystals of 2 were obtained using the same method as for crystallization of compound 1. The crystals were washed with diethyl ether and dried in vacuum. (0.35g, $56 \%$ yield based on $\mathrm{Zn})$. Anal. Calcd for $\mathrm{C}_{16} \mathrm{H}_{22} \mathrm{~N}_{6} \mathrm{~S}_{2} \mathrm{Zn}$ : $\mathrm{C}$ 44.9, H 5.2, N 19.6; Found: C 44.2, H 5.1, N 19.1. FT-IR ( $\left.\mathrm{cm}^{-1}\right)$ : 481(w), 690(w), 751(w), 811(m), 917(w), 1052(s), 1117(m), 1230(w), 1208(w) 1271(w), 1389(m), 1454(m), 1471(m), 1551(vs), 2049(vs; NCS), 2072(vs; NCS), 2932(w), 2956(w), 3126(w).

\section{2. 3. Synthesis of $\left\{\left[\mathrm{Zn}(\mu-b i b)_{2}\right]\left(\mathrm{ClO}_{4}\right)_{2} \cdot\left(\mathrm{Et}_{2} \mathrm{O}\right)_{0.5} \cdot\left(\mathrm{H}_{2} \mathrm{O}\right)_{0.25}\right\}_{\mathrm{n}}$ (3).}

The bib (0.085 g, $0.45 \mathrm{mmol})$ was added to a solution of $\mathrm{Zn}\left(\mathrm{ClO}_{4}\right)_{2} \cdot 6 \mathrm{H}_{2} \mathrm{O}(0.083 \mathrm{~g}, 0.22$ $\mathrm{mmol})$ in DMF (15 mL) and the reaction mixture was stirred at room temperature for $2 \mathrm{~h}$ and then filtered. Colorless needle-shaped single crystals of $\mathbf{3}$ were obtained by slow evaporation of the solvent at room temperature in a Petri dish after 2-3 days. The crystals were washed with EtOH and diethyl ether and dried in vacuum. (0.07g, 51\% yield based on $\mathrm{Zn})$. Anal. Calcd for $\mathrm{C}_{22} \mathrm{H}_{33.5} \mathrm{Cl}_{2} \mathrm{~N}_{8} \mathrm{O}_{8.8} \mathrm{Zn}$ : C 38.5, $\mathrm{H} 4.9$, N 16.3; Found: C 38.4, H 4.6, N 16.5. FT-IR $\left(\mathrm{cm}^{-1}\right):$ 623(s; $\left.\mathrm{ClO}_{4}\right), 658(\mathrm{~s}), 766(\mathrm{~m}), 842(\mathrm{~m}), 956(\mathrm{~s}), 1095\left(\mathrm{vs} ; \mathrm{ClO}_{4}\right), 1245(\mathrm{~s}), 1295(\mathrm{w})$, 1360(w), 1385(w), 1454(m), 1526(s), 1538(s), 1675(s), 2959(w), 3054(w), 3130(s).

\section{2. 4. Synthesis of $\left\{\left[\mathrm{Zn}(\mu-\mathrm{bmib})_{2}\right]\left(\mathrm{ClO}_{4}\right)_{2} \cdot\left(\mathrm{H}_{2} \mathrm{O}\right)_{4}\right\}_{\mathrm{n}}(4)$.}

A solution of $24 \mathrm{mg}(0.11 \mathrm{mmol})$ bmib in $3 \mathrm{~mL}$ acetone was carefully layered over a solution of $20 \mathrm{mg}(0.054 \mathrm{mmol})$ of $\mathrm{Zn}\left(\mathrm{ClO}_{4}\right)_{2} \cdot 6 \mathrm{H}_{2} \mathrm{O}$ in $3 \mathrm{~mL} \mathrm{H} \mathrm{H}_{2} \mathrm{O}$ at room temperature. After five days, colorless block-like crystals of $\mathbf{4}$ were obtained. The supernatant solvent was removed; the crystals were washed with EtOH and diethyl ether and dried in vacuum (22 $\mathrm{mg}, 59 \%$ yield based on $\mathrm{Zn}$ ). Anal. Calcd for $\mathrm{C}_{24} \mathrm{H}_{40} \mathrm{Cl}_{2} \mathrm{~N}_{8} \mathrm{O}_{10} \mathrm{Zn}$ : C 39.1, H 5.4, N 15.2; Found: C 38.8, H 5.2, N 15.1. FT-IR ( $\left.\mathrm{cm}^{-1}\right)$ : 623(s; $\left.\mathrm{ClO}_{4}\right), 658(\mathrm{~s}), 767(\mathrm{~m}), 843(\mathrm{~m}), 955(\mathrm{~s}), 1094(\mathrm{vs}$; $\left.\mathrm{ClO}_{4}\right), 1245(\mathrm{~s}), 1294(\mathrm{w}), 1358(\mathrm{w}), 1385(\mathrm{w}), 1454(\mathrm{~m}), 1526(\mathrm{~s}), 1538(\mathrm{~s}), 1675(\mathrm{~s}), 2961(\mathrm{~m})$, 3054(w), 3130(s).

Caution: Perchlorate compounds are potentially explosive and should be handled with care.

\section{3. X-ray crystallographic study}


X-ray data were collected on an Oxford Diffraction Gemini for $\mathbf{1}$ and $\mathbf{3}$ and on a BrukerApexII for 2 and 4 using MoK $\alpha$ radiation. The structures were solved using direct methods and refined using a full-matrix least squares procedure based on $F^{2}$ using all data [15]. Hydrogen atoms were placed at geometrically estimated positions. Details relating to the crystals and the structural refinements are presented in Table 1. In compound 3 the guest molecules of diethylether and water have been refined with isotropic thermal parameters and without the hydrogen atoms. One ligand has a $\mathrm{N}(2)-\mathrm{C}(4)-\mathrm{C}(5 \mathrm{a}, \mathrm{b})-\mathrm{C}(6 \mathrm{a}, \mathrm{b})-\mathrm{C}(7)-\mathrm{N}(4)$ chain with a disorder modelled with $50 \%-50 \%$ for $\mathrm{C} 5 \mathrm{a} / \mathrm{C} 5 \mathrm{~b}, \mathrm{C} 6 \mathrm{a} / \mathrm{C} 6 \mathrm{~b}$ and isotropic thermal parameter. To avoid short contact the hydrogens have been removed for the whole carbon chain. To avoid unreasonable $\mathrm{C}-\mathrm{C}$ distances, restrains have been imposed. In compound $\mathbf{4}$ the clathrate water molecule is disorder $50 \%$ over two position and has been refined without hydrogens and with isotropic thermal parameters. Full details of crystal data and the structure refinements, in CIF format, are available as supporting information. CCDC reference numbers $930745-930748$ for 1-4.

\section{Results and Discussion}

\section{1. Synthesis and Spectroscopic Characterization}

Compounds 1-4 were obtained by one pot reactions at room temperature. Treatment of bbd with $\mathrm{ZnI}_{2}($ molar ratio $=1: 1)$ in $\mathrm{CH}_{3} \mathrm{OH}$ gave rise to $1 \mathrm{D}$ polymeric chain $\left[\mathrm{ZnI}_{2}(\mu-\mathrm{bbd})\right]_{\mathrm{n}}(\mathbf{1})$ (68\% yield). Analogous reactions of bbd with $\mathrm{ZnCl}_{2}$ and $\mathrm{KSCN}$ in $\mathrm{CH}_{3} \mathrm{CN}$ or $\mathrm{CH}_{3} \mathrm{OH}$ with a molar ratio of 1:2:2, produced the $1 \mathrm{D}$ polymeric chain $\left[\mathrm{Zn}(\mathrm{NCS})_{2}(\mu-\mathrm{bbd})\right]_{\mathrm{n}}(2)(56 \%$ yield $)$. One-pot reaction of $\mathrm{Zn}\left(\mathrm{ClO}_{4}\right)_{2} \cdot 6 \mathrm{H}_{2} \mathrm{O}$ and imizadolyl-based ligand (bib) (molar ratio = 1:2) in DMF with stirring at room temperature for $2 \mathrm{~h}$, afforded the coordination network $\{[\mathrm{Zn}(\mu-$ bib $\left.\left.)_{2}\right]\left(\mathrm{ClO}_{4}\right)_{2} \cdot\left(\mathrm{Et}_{2} \mathrm{O}\right)_{0.5} \cdot\left(\mathrm{H}_{2} \mathrm{O}\right)_{0.25}\right\}_{\mathrm{n}}$ (3) $\left(51 \%\right.$ yield). The related $\left\{\left[\mathrm{Zn}(\mu-\mathrm{bib})_{2}\right]\left(\mathrm{ClO}_{4}\right)_{2}\right\}_{\mathrm{n}}$ complex [11d] was synthesized by using the same starting material as used for $\mathbf{3}$, in $\mathrm{H}_{2} \mathrm{O} / \mathrm{C}_{2} \mathrm{H}_{5} \mathrm{OH}$ solvent under hydrothermal condition. By comparison, the $\left\{\left[\mathrm{Zn}(\mathrm{bib})_{2}\right]\left(\mathrm{ClO}_{4}\right)_{2}\right\}_{\mathrm{n}}$ coordination polymer has 1D double chain structure, while complex 3 possesses a 3D 3-fold interpenetrating framework with $10^{3}$-ths topology. Thus, parameters such as the reaction temperature and solvent system have crucial effects on the structure and topology of these complexes. Compound $\left\{\left[\mathrm{Zn}(\mu-\mathrm{bmib})_{2}\right]\left(\mathrm{ClO}_{4}\right)_{2} \cdot\left(\mathrm{H}_{2} \mathrm{O}\right)_{4}\right\}_{\mathrm{n}}(4)$ was obtained from slow diffusion method by layering an acetone solution of bmib over a solution of $\mathrm{Zn}\left(\mathrm{ClO}_{4}\right)_{2} \cdot 6 \mathrm{H}_{2} \mathrm{O}$ in $\mathrm{H}_{2} \mathrm{O}$ in a molar ratio of $2: 1$ at room temperature (59\% yield). 4 shows a 
1D double chain structure which extends to a $3 \mathrm{D}$ supramolecular framework by $\mathrm{C}-\mathrm{H} \cdots \mathrm{O}$ hydrogen bonds to the perchlorate anions. All our attempts to synthesize the analogous complexes of $\mathbf{3}$ and $\mathbf{4}$ with the bbd ligand failed. Large steric hindrance due to the presence of two methyl substituents on the pyrazole rings prevent simultaneous coordination of four bulky 3,5-dimethyl pyrazole groups to a metal center. All the colorless complexes are stable at room temperature. Powders of $\mathbf{1}$ and $\mathbf{2}$ are soluble in MeCN, DMF and DMSO. Compound 3 is insoluble in common organic solvents such as $\mathrm{CHCl}_{3}, \mathrm{MeCN}$, DMF and DMSO whereas the powder of 4 is moderately soluble in DMF and DMSO. The elemental analyses results for $\mathrm{C}, \mathrm{H}, \mathrm{N}$, match well with the composition of crystal structure determinations.

The infrared spectra of the complexes 1 and $\mathbf{2}$ exhibit characteristic bands of the coordinated $\mu$-bbd ligands at 2934(m), 1551(vs), 1466 (s), 1421 (s) and 1376 (s) $\mathrm{cm}^{-1}$ for 1 and 2932(m), 1551(vs), $1471(\mathrm{~m}), 1454(\mathrm{~m})$ and $1389(\mathrm{~m}) \mathrm{cm}^{-1}$ for 2 . The $1551 \mathrm{~cm}^{-1}$ band correspond to the stretching vibration of $\mathrm{C}=\mathrm{N}$ bonds typical of the pyrazole rings of $\mu$-bbd ligands. This band is shifted to lower frequencies with respect to the spectrum of the free 3,5-dimethylpyrazole $\left(1595 \mathrm{~cm}^{-1}\right)[10 \mathrm{~b}, 16]$. The infrared spectrum of 2 also shows two adjacent intense bands at 2049 and $2072 \mathrm{~cm}^{-1}$ assigned to $\mathrm{CN}$ stretching vibration of two different N-coordinated terminal thiocyanate groups. This observation could be rationalized by the existence of two different bond lengths for the $\mathrm{CN}$ bonds of the SCN-groups in the crystal structure of complex 2 (Table 2). The infrared spectra of 3 and 4 show characteristic bands of the coordinated bib and bmib ligands in the range of $600-1550 \mathrm{~cm}^{-1}$, dominated by imidazole ring stretching, bending and deformation vibrations. The bands in the range of $2860-2960 \mathrm{~cm}^{-1}$ may be attributed to the $\mathrm{C}-\mathrm{H}$ stretching vibrations of $-\left(\mathrm{CH}_{2}\right)_{4}$ - spacer group in the linker ligands. The infrared spectra of the complexes 3 and $\mathbf{4}$ also display two sharp bands at 622 and $1095 \mathrm{~cm}^{-1}$ for 3 and at 623 and $1104 \mathrm{~cm}^{-1}$ for 4 due to the vibration bands of $\mathrm{ClO}_{4}^{-}$ counter anion. The bands at $3130 \mathrm{~cm}^{-1}$ for 3 and $3140 \mathrm{~cm}^{-1}$ for 4 and also weak broad peaks appear in the range of $3520-3630 \mathrm{~cm}^{-1}$, attributed to the vibration bands of water guest molecules, present in the structure of 3 and 4 . The FT-IR results are consistent with the crystallographic study.

\section{2. Description of crystal structures}

\section{2. 1. Crystal structure of $\left[\mathrm{ZnI}_{2}(\mu-b b d)\right]_{n}(1)$}

Single crystal X-ray structural analysis reveals that $\mathbf{1}$ crystallizes in the monoclinic space group C2/c. The asymmetric unit of 1 contains half $\mathrm{Zn}(\mathrm{II})$ ion, half centro-symmetric $\mu$-bbd 
ligand and one iodo ligand (Fig. 1a). The $\mathrm{Zn}(\mathrm{II})$ ion reside on a 2-fold axis and is coordinated by two symmetry-related iodide anions with Zn-I distance of 2.5908(4) $\AA$ and two N atoms of two crystallographic equivalent $\mu$-bbd ligands with $\mathrm{Zn}-\mathrm{N}$ distance of 2.053(2) $\AA$ in a distorted tetrahedral $\mathrm{ZnN}_{2} \mathrm{I}_{2}$ coordination geometry. These distances are comparable with the corresponding values reported for the dimer $\left[\mathrm{Zn}_{2} \mathrm{I}_{4}\left(\operatorname{tr}_{2} \mathrm{eth}\right)_{2}\right][17]\left[\operatorname{tr}_{2} \mathrm{eth}=1,2-\mathrm{bis}(1,2,4\right.$-triazol4-yl)ethane], monomer [ $\left.\mathrm{ZnI}_{2}\left(\mathrm{BpsMe}_{2}\right)\right]$ [18] [BpsMe= Bis(3,5-dimethylpyrazol-1-yl)silane] and other $\mathrm{N}$-donor adducts of $\mathrm{ZnI}_{2}$ with an $\mathrm{N}_{2} \mathrm{I}_{2}$ donor set. A structural comparison between 1 and $\left[\mathrm{Zn}_{2} \mathrm{I}_{4}\left(\operatorname{tr}_{2} \mathrm{eth}\right)_{2}\right]$ and $\left[\mathrm{ZnI}_{2}(\mathrm{BpsMe})\right]$ complexes shows that the variation of the linker ligand has decisive influence on the structural topology of the complexes.
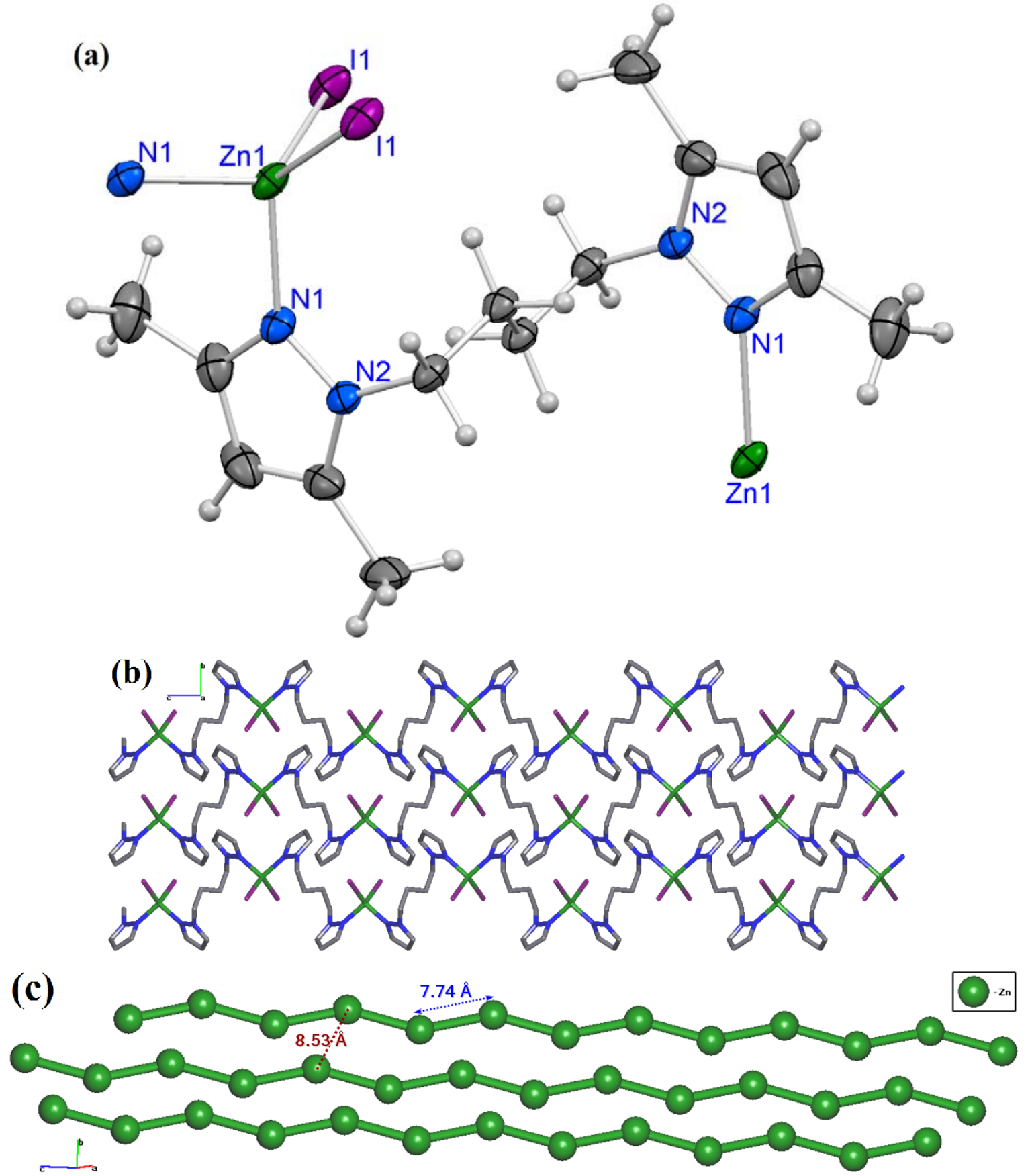
Fig. 1. The structure of $\left[\mathrm{ZnI}_{2}(\mu-b b d)\right]_{\mathrm{n}}$ (1). (a) View of the $\left[\mathrm{ZnI}_{2}(\mu-b b d)\right]$ unit in $\mathbf{1}$ with a labeling scheme for non- $\mathrm{H}$ and $\mathrm{C}$ atoms. (b) View of three parallel adjacent 1D chains along $a$ axis; the chains run along the $c$ axis. $\mathrm{H}$ atoms and methyl substituents were omitted for clarity (c) Schematic view of three neighboring zig-zag chains; $\mathrm{Zn} \cdots \mathrm{Zn}$ distance within each polymeric chain is $7.74 \AA$, while the shortest inter-chain $\mathrm{Zn} \cdots \mathrm{Zn}$ distance is $8.53 \AA$.

The bond angles around the metal center range from $98.3^{\circ}$ to $121.7^{\circ}$ (Table 2). The remarkable deviations from the ideal tetrahedral angle can be explained with the need of accommodating the organic ligand and the halogen atoms around the metal center. The bbd molecule acts as a bidentate bridging ligand coordinating metal centers through its nitrogen atoms to form a polymeric one-dimensional zig-zag chain structure along the crystallographic $c$ axis (Fig. 1b), with $\mathrm{Zn} \cdots \mathrm{Zn}$ separation of $7.74 \AA$. The shortest $\mathrm{Zn} \cdots \mathrm{Zn}$ separation of $8.53 \AA$ between adjacent neutral chains is governed by the steric hindrance of the pyrazolyl rings (Fig. 1c). All the $\mu$-bbd ligands are crystallographically equivalent and exhibit a gauche-antigauche' conformation with a (Zn)N-to-N(Zn) distance of $6.33 \AA$. The dihedral angle between the mean planes of the pyrazole rings of the centro-symmetric bbd ligand is $0^{\circ}$. Whereas the 1D chains in the crystal structure of $\mathbf{1}$ pack in a manner such that the pyrazole rings of different bbd ligands from adjacent chains are strictly parallel (dihedral angle $\left.=0^{\circ}\right)($ Fig. $1 \mathrm{~b}$ ), though the centroid $\cdots$ centroid distances of $5.05 \AA$ imply no significant $\pi \cdots \pi$ interaction between adjacent chains.

\section{2. 2. Crystal structure of $\left[\mathrm{Zn}(\mathrm{NCS})_{2}(\mu-b b d)\right]_{n}(2)$}

Compound 2 crystallizes in the monoclinic space group $P 2_{1} / n$. The asymmetric unit contains two $\mathrm{Zn}(\mathrm{NCS})_{2}$ fragments and two $\mu$-bbd ligands (Fig. 2a). The $\mathrm{Zn}$ (II) ions are in the center of a distorted tetrahedral $\mathrm{ZnN}_{4}$ arrangement coordinating two nitrogen atoms from two distinct $\mu$-bbd ligands and two nitrogen atoms from two terminal N-bonded thiocyanate ions. The Zn$\mathrm{N}(\mu$-bbd) distances are comprised in the range 2.009(2)-2.017(2) $\AA$ and are similar to those reported for $\left[\mathrm{Zn}(\mathrm{SCN})_{2}(\mathrm{api})\right]_{\mathrm{n}}$ [19] (api= 1-(3-aminopropyl)-imidazole). The other $\mathrm{Zn}$ $\mathrm{N}$ (thiocyanate) bond distances are comprised in the range 1.952(3)-1.957(3) $\AA$ (Table 2). The NCS ligands in 2, show very small distortions from linearity (N-C-S ca. $\left.179^{\circ}\right)$ and bind to the metal in a non-linear mode with $\mathrm{Zn}-\mathrm{N}-\mathrm{C}$ angles in the range $142.9(3)^{\circ}-159.9(3)^{\circ}$. The bond angles around $\mathrm{Zn}(\mathrm{II})$ are slightly distorted from the ideal tetrahedral bond angle and range from $104.8(1)^{\circ}$ to $116.8(1)^{\circ}$.

As in $\mathbf{1}$, in the structure of $\mathbf{2}$, the $\mathrm{Zn}(\mathrm{II})$ ions are connected via $\mu$-bbd ligands to form a $1 \mathrm{D}$ zig-zag chain structure. In contrast to $\mathbf{1}$, the $\mu$-bbd ligands in $\mathbf{2}$ have two different 
conformations with two different $(\mathrm{Zn}) \mathrm{N}$-to- $\mathrm{N}(\mathrm{Zn})$ distances: $6.48 \AA$ for the gauche-antigauche' (red) and $7.54 \AA$ for the anti-anti-anti (blue) conformations [Fig. 2b].This can be attributed to the effect of the counter ions on the conformation of the flexible $\mu$-bbd ligands $[10 \mathrm{~g}, \mathrm{~h}]$. The different conformations of the ligands cause two different $\mathrm{Zn} \cdots \mathrm{Zn}$ distances (7.55 and $8.08 \AA$ ) in the chain structure of 2.

(a)
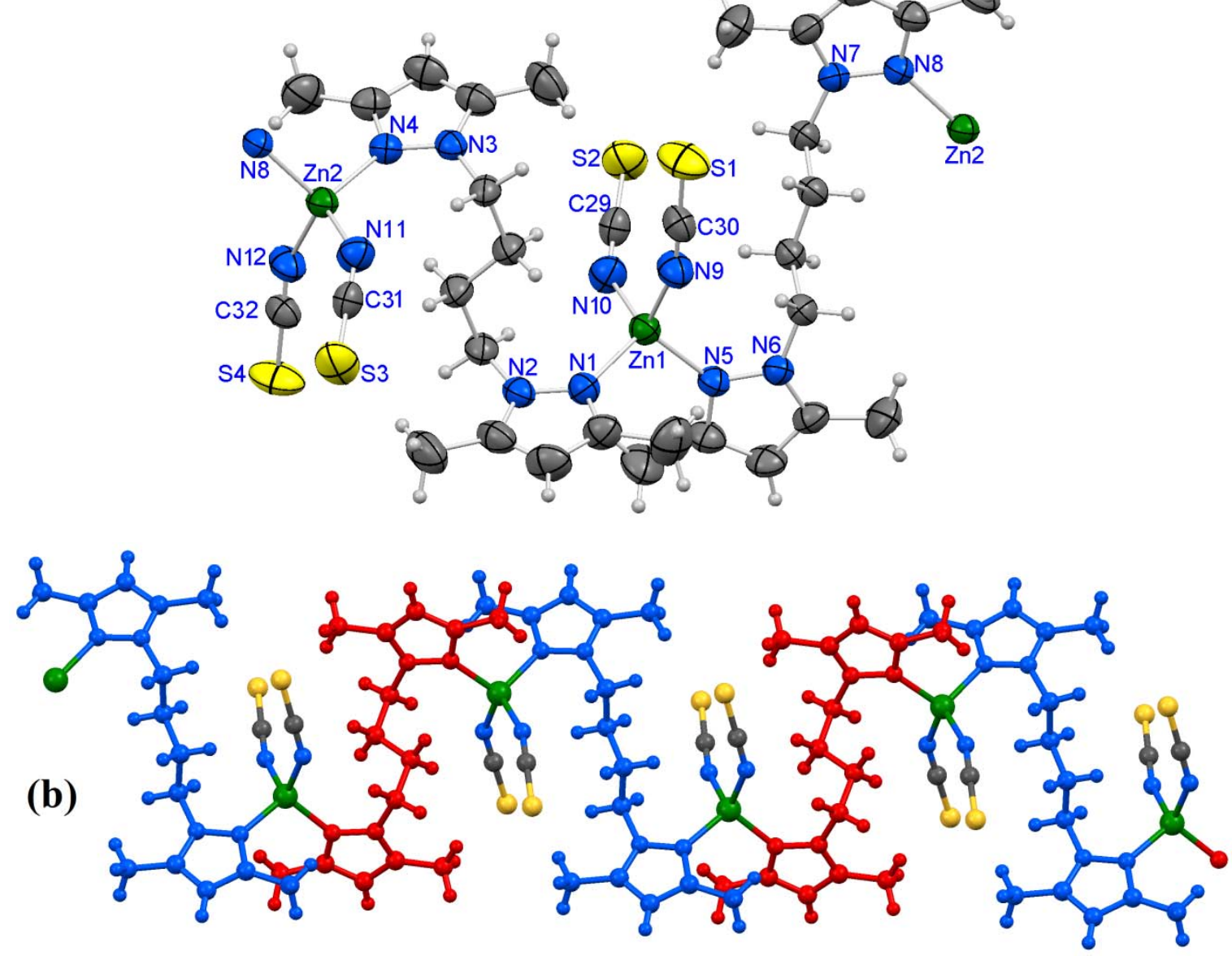

Fig. 2. The structure of $\left[\mathrm{Zn}(\mathrm{NCS})_{2}(\mu-\mathrm{bbd})\right]_{\mathrm{n}}$ (2). (a) asymmetric unit of $\mathbf{2}$ with labeling scheme. (b) $1 \mathrm{D}$ zig-zag structure of $\mathbf{2}$ containing a sequence of $\mu$-bbd ligands with two different conformations, gauche-anti-gauche' (red) and anti-anti-anti (blue).

The dihedral angle between the two pyrazole rings in both conformations are similar and equal to $3.2^{\circ}$ and $3.7^{\circ}$, respectively. The $\mu$-bbd ligands in $\mathbf{1}$ and the red colored ligands in $\mathbf{2}$, exhibit the same structural conformations but with different $\mathrm{N}$-to-N distances. This may be ascribed to the different torsion angles of $-\left(\mathrm{CH}_{2}\right)_{4^{-}}$spacer in the structures (Table 4). The calculated dihedral angles between the ring mean planes for the bbd ligands in $\mathbf{1}$ and $\mathbf{2}$ are close to zero, because the usual convention is to report such dihedral angles in the range 0 $90^{\circ}$; however, the strictly parallel rings would be better described as antiparallel, with a dihedral angle of $180^{\circ}$, resulting in $\mathrm{Zn}-\mathrm{N}$ bonds that point in exactly opposite directions.As 
for $\mathbf{1}$, adjacent chains in the structure of $\mathbf{2}$ have no significant intermolecular interactions and there are no pyrazole ring-stacking interactions within or between chains; nevertheless the centroid $\cdots$ centroid distance of $4.88 \AA$ between the pyrazole rings of the adjacent chains shows a closer proximity in the structure of $\mathbf{2}$, compared to the packing of chains in $\mathbf{1}$. Coordination polymers of $\mathrm{Zn}(\mathrm{II})$ ion with flexible bis(pyrazole-1-yl)alkane ligands are uncommon and only a few examples are reported in the literature [20].

Table 1. Crystallographic data and structure refinement details for 1-4.

\begin{tabular}{|c|c|c|c|c|}
\hline Compound & 1 & 2 & 3 & 4 \\
\hline Formula & $\mathrm{C}_{14} \mathrm{H}_{22} \mathrm{I}_{2} \mathrm{~N}_{4} \mathrm{Zn}$ & $\mathrm{C}_{16} \mathrm{H}_{22} \mathrm{~N}_{6} \mathrm{~S}_{2} \mathrm{Zn}$ & $\mathrm{C}_{22} \mathrm{H}_{33.5} \mathrm{Cl}_{2} \mathrm{~N}_{8} \mathrm{O}_{8.75} \mathrm{Zn}$ & $\mathrm{C}_{24} \mathrm{H}_{40} \mathrm{Cl}_{2} \mathrm{~N}_{8} \mathrm{O}_{10} \mathrm{Zn}$ \\
\hline formula mass & 565.53 & 427.89 & 686.34 & 736.91 \\
\hline$T(\mathrm{~K})$ & $130(1) \mathrm{K}$ & 293(2) K & $130(1) \mathrm{K}$ & $293(2) \mathrm{K}$ \\
\hline crystsyst & Monoclinic & Monoclinic & Orthorombic & Tetragonal \\
\hline space group & $C 2 / c$ & $P 2_{1} / n$ & $F 2 d d$ & $I 4_{1} /$ acd \\
\hline $\mathrm{a}(\AA)$ & $12.6785(6)$ & $13.9476(9)$ & $21.3477(15)$ & $18.9727(7)$ \\
\hline $\mathrm{b}(\AA)$ & $11.4031(6)$ & $23.4840(16)$ & $22.9862(16)$ & $18.9727(7)$ \\
\hline$c(\AA)$ & $15.0587(8)$ & $14.0807(10)$ & $24.297(2)$ & $17.9724(12)$ \\
\hline$\beta\left(^{\circ}\right)$ & $112.944(6)$ & $116.1540(10)$ & 90.00 & 90.00 \\
\hline$V\left(\AA^{3}\right)$ & $2004.86(18)$ & $4139.8(5)$ & $11922.6(15)$ & $6469.4(5)$ \\
\hline Z & 4 & 8 & 16 & 8 \\
\hline Dcalcd $\left(\mathrm{g} \mathrm{cm}^{-3}\right)$ & 1.874 & 1.373 & 1.529 & 1.513 \\
\hline no. of reflns collected & 5425 & 13296 & 10082 & 45502 \\
\hline no. of independentreflns & 2227 & 6339 & 5262 & 2489 \\
\hline$R_{\text {int }}$ & 0.0247 & 0.0795 & 0.0808 & 0.1309 \\
\hline data/restraints/params & $2227 / 0 / 98$ & $6339 / 0 / 451$ & $4794 / 155 / 363$ & $2489 / 0 / 102$ \\
\hline GOF on $F^{2} /$ Flack parameter & 1.029 & 0.998 & $1.031 / 0.07(5)$ & 1.023 \\
\hline $\mathrm{R} 1[I>2 \sigma(I)]$ & 0.0246 & 0.0474 & 0.1013 & 0.0740 \\
\hline$w_{2}$ (all data) & 0.0336 & 0.1424 & 0.3121 & 0.2914 \\
\hline
\end{tabular}

All of these compounds have been prepared by rigid or less flexible linker ligands. Zincbased coordination polymers containing flexible pyrazole based ligands with $-\left(\mathrm{CH}_{2}\right)_{\mathrm{n}^{-}}(\mathrm{n} \geq 4)$ as a spacer group have not been observed in any polymeric systems prior to this work. In contrast, the zinc complexes of this type of ligands with $n=1,2,3$ which have been published in the literature, have only monomeric or dimeric structures [21]. With the main objective to understand the effect produced on the structure of the coordination polymers by exchanging the halogen with the pseudo-halogen, we have been able to synthesize complexes $\mathbf{1}$ and $\mathbf{2}$ as the first examples of zinc(II) coordination polymers with the bis(pyrazole-1-yl)alkane ligands.

\section{2. 3. Crystal structure of $\left\{\left[\mathrm{Zn}(\mu-b i b)_{2}\right]\left(\mathrm{ClO}_{4}\right)_{2} \cdot\left(\mathrm{Et}_{2} \mathrm{O}\right)_{0.5} \cdot\left(\mathrm{H}_{2} \mathrm{O}\right)_{0.25}\right\}_{\mathrm{n}}(3)$}


Single crystal X-ray studies indicate that compound 3 crystallizes in the orthorhombic space group F2dd. The asymmetric unit consists of a $\left[\mathrm{Zn}(\mathrm{bib})_{2}\right]^{2+}$ cation and two $\mathrm{ClO}_{4}{ }^{-}$counterions (Fig. 3a), together with a half of diethyl ether and a quarter of water as guest molecules. The $\mathrm{Zn}$ (II) center shows a slightly distorted $\mathrm{ZnN}_{4}$ tetrahedral geometry by four coordinated nitrogen atoms from four distinct $\mu$-bib ligands. The $\mathrm{Zn}-\mathrm{N}$ bond distances and $\mathrm{N}-\mathrm{Zn}-\mathrm{N}$ bond angles (Table 3) are comparable to those observed for $\left\{\left[\mathrm{Zn}(\mathrm{bib})_{2}\right]\left(\mathrm{ClO}_{4}\right)_{2}\right\}_{\mathrm{n}}[11 \mathrm{~d}]$ and are in the normal range for such coordination bonds.

Table 2.Selected bond lengths $(\AA)$ and angles $\left({ }^{\circ}\right)$ for $\mathbf{1}$ and $\mathbf{2}$.

\begin{tabular}{|c|c|c|c|c|c|}
\hline \multicolumn{2}{|c|}{ (1) } & \multicolumn{2}{|c|}{ (2) } & \multicolumn{2}{|l|}{ (2) } \\
\hline \multicolumn{6}{|c|}{ Bond lengths/Å } \\
\hline $\mathrm{Zn} 1-\mathrm{N} 1$ & $2.053(2)$ & $\mathrm{Zn1-N1}$ & $2.017(2)$ & $\mathrm{Zn} 2-\mathrm{N} 4$ & $2.009(2)$ \\
\hline Zn1-I1 & $2.5908(4)$ & Zn1-N5 & $2.013(2)$ & Zn2-N8 & $2.013(2)$ \\
\hline \multirow[t]{6}{*}{ N1-N2 } & $1.374(3)$ & Zn1-N9 & $1.957(3)$ & Zn2-N11 & $1.952(3)$ \\
\hline & & $\mathrm{Zn} 1-\mathrm{N} 10$ & $1.956(3)$ & $\mathrm{Zn} 2-\mathrm{N} 12$ & $1.956(3)$ \\
\hline & & $\mathrm{S} 1-\mathrm{C} 30$ & $1.605(3)$ & S3-C31 & $1.596(3)$ \\
\hline & & S2-C29 & $1.605(3)$ & S4-C32 & $1.602(3)$ \\
\hline & & C30-N9 & $1.144(4)$ & C31-N11 & $1.158(4)$ \\
\hline & & C29-N10 & $1.144(4)$ & C32-N12 & $1.140(4)$ \\
\hline \multicolumn{6}{|c|}{ Bond angles $/^{\circ}$} \\
\hline I1-Zn1-N1 & $102.64(6)$ & N1-Zn1-N5 & $109.4(1)$ & Zn1-N9-C30 & $159.9(3)$ \\
\hline I1-Zn1-I1a & $110.76(2)$ & N1-Zn1-N9 & $104.9(1)$ & Zn1-N10-C29 & $142.9(3)$ \\
\hline I1-Zn1-N1a & $121.65(6)$ & N1-Zn1-N10 & $116.8(1)$ & N9-C30-S1 & $178.8(3)$ \\
\hline N1a-Zn1-N1 & $98.25(13)$ & N5-Zn1-N9 & 115.1(1) & N10-C29-S2 & $179.4(3)$ \\
\hline \multirow[t]{8}{*}{ I1a-Zn1-N1a } & $102.64(6)$ & N5-Zn1-N10 & $106.1(1)$ & Zn2-N11-C31 & $145.0(3)$ \\
\hline & & N9-Zn1-N10 & $104.8(1)$ & $\mathrm{Zn2-N12-C32}$ & $156.7(3)$ \\
\hline & & N4-Zn2-N8 & $108.5(1)$ & N11-C31-S3 & $179.4(3)$ \\
\hline & & N4-Zn2-N11 & $116.7(1)$ & N12-C32-S4 & 179.1(3) \\
\hline & & N4-Zn2-N12 & $106.1(1)$ & & \\
\hline & & N8-Zn2-N11 & 105.1(1) & & \\
\hline & & N8-Zn2-N12 & $115.7(1)$ & & \\
\hline & & N11-Zn2-N12 & $105.1(1)$ & & \\
\hline
\end{tabular}

Although the $\mathrm{Zn}(\mathrm{II})$ centers in complexes 2 and 3 have the same $\left(\mathrm{ZnN}_{4}\right)$ coordination environments, the structures of the final products are very different. In the structure of $\mathbf{3}$, two neighboring $\mathrm{Zn}$ (II) ions are interconnected by a double bridge of $\mu$-bib ligands, shown in blue color in Fig. 3b, to form a 22-membered macrocyclic $\left[\mathrm{Zn}(\mathrm{bib})_{2} \mathrm{Zn}\right]$ dimeric unit. The dimeric units are linked together by single bridge $\mu$-bib ligands (red colored), to form an infinite 3D coordination network (Fig. 3c). 

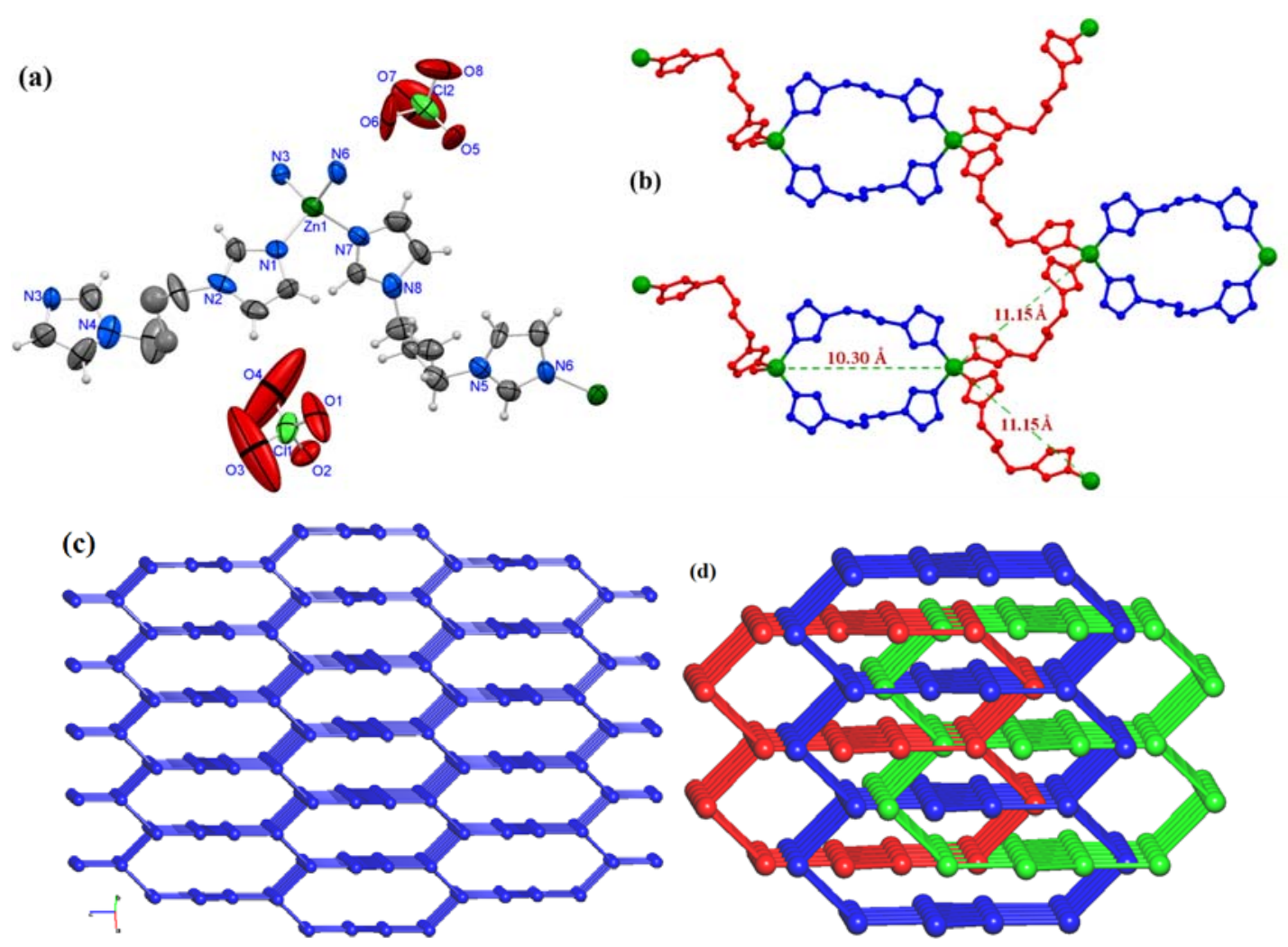

Fig. 3.(a) Coordination environment of $\mathrm{Zn}(\mathrm{II})$ in $\mathbf{3}$ with a labeling scheme for asymmetric unit without disordered guest molecules. (b) View of a section of the 3D net which show different ligand conformations and $\mathrm{Zn} \cdots \mathrm{Zn}$ distances. (c) Schematic illustration of a single 3D $10^{3}$-ths network (d) Schematic representation of the 3-fold interpenetrating $10^{3}$-ths topology of crystal 3. All $\mathrm{H}$ atoms in (a) and (b) have been omitted for clarity.

Table 3.Selected bond lengths $(\AA)$ and angles $\left({ }^{\circ}\right)$ for $\mathbf{3}$ and $\mathbf{4}$.

\begin{tabular}{|c|c|c|c|c|c|}
\hline \multicolumn{2}{|c|}{ (3) } & \multicolumn{2}{|c|}{ (3) } & \multicolumn{2}{|c|}{ (4) } \\
\hline \multicolumn{6}{|c|}{ Bond lengths/Å } \\
\hline Zn1-N1 & $1.979(13)$ & $\mathrm{Cl1}-\mathrm{O} 3$ & $1.386(8)$ & Zn1-N1 & $1.989(4)$ \\
\hline Zn1-N3 & $1.981(12)$ & Cl1-O4 & $1.404(8)$ & $\mathrm{C} 11-\mathrm{O} 1$ & $1.381(5)$ \\
\hline Zn1-N6 & $1.956(14)$ & $\mathrm{Cl} 2-\mathrm{O} 5$ & $1.394(7)$ & $\mathrm{Cl1-O2}$ & $1.416(5)$ \\
\hline Zn1-N7 & $1.989(13)$ & $\mathrm{Cl} 2-\mathrm{O} 6$ & $1.403(7)$ & & \\
\hline $\mathrm{Cl1}-\mathrm{O} 1$ & $1.381(7)$ & $\mathrm{Cl} 2-\mathrm{O} 7$ & $1.377(7)$ & & \\
\hline $\mathrm{Cl} 1-\mathrm{O} 2$ & $1.394(7)$ & $\mathrm{Cl} 2-\mathrm{O} 8$ & $1.394(7)$ & & \\
\hline \multicolumn{6}{|c|}{ Bond angles $/^{\circ}$} \\
\hline N1-Zn1-N3 & $109.2(4)$ & $\mathrm{O} 2-\mathrm{Cl1}-\mathrm{O} 3$ & $109.2(6)$ & N1-Zn1-N1 & $97.7(2)$ \\
\hline N1-Zn1-N6 & $111.7(6)$ & $\mathrm{O} 2-\mathrm{Cl1}-\mathrm{O} 4$ & 107.4(6) & N1-Zn1-N1 & $115.7(1)$ \\
\hline N1-Zn1-N7 & $106.5(5)$ & O3-Cl1-O4 & 109.0(6) & O1-Cl1-O1 & $109.6(6)$ \\
\hline N3-Zn1-N6 & $111.6(6)$ & $\mathrm{O} 5-\mathrm{Cl} 2-\mathrm{O} 6$ & $108.2(5)$ & $\mathrm{O} 1-\mathrm{Cl1}-\mathrm{O} 2$ & $111.5(4)$ \\
\hline N3-Zn1-N7 & $111.7(5)$ & $\mathrm{O} 5-\mathrm{Cl} 2-\mathrm{O} 7$ & $111.4(6)$ & $\mathrm{O} 1-\mathrm{Cl1}-\mathrm{O} 2$ & $107.2(3)$ \\
\hline N6-Zn1-N7 & $106.1(5)$ & $\mathrm{O} 5-\mathrm{Cl} 2-\mathrm{O} 8$ & $110.0(5)$ & $\mathrm{O} 2-\mathrm{Cl1}-\mathrm{O} 2$ & $109.9(5)$ \\
\hline $\mathrm{O} 1-\mathrm{Cl1}-\mathrm{O} 2$ & $111.1(5)$ & $\mathrm{O} 6-\mathrm{Cl} 2-\mathrm{O} 7$ & 109.5(6) & & \\
\hline $\mathrm{O} 1-\mathrm{Cl1}-\mathrm{O} 3$ & $110.4(6)$ & $\mathrm{O} 6-\mathrm{C} 12-\mathrm{O} 8$ & $108.2(6)$ & & \\
\hline $\mathrm{O} 1-\mathrm{Cl1}-\mathrm{O} 4$ & $109.7(6)$ & $\mathrm{O} 7-\mathrm{Cl} 2-\mathrm{O} 8$ & 109.4(5) & & \\
\hline
\end{tabular}


The alkyl chain of the blue colored $\mu$-bib ligands adopts a gauche-anti-gauche' conformation. The dihedral angle between the mean planes of two imidazolyl rings is 1.86 ${ }^{\circ}$ and the N-to-N distances is $8.06 \AA$ (Table 4$)$. The red colored $\mu$-bib ligands show a gaucheanti-gauche conformation with the dihedral angle of $12.39^{\circ}$ and the N-to-N distance of 7.69 $\AA$ which are different from those in the blue colored bib ligands. As shown in Fig. 3b, two different $\mathrm{Zn} \cdots \mathrm{Zn}$ distance (10.30 and $11.15 \AA$ ) are observed in the network, as a consequence of the two different types of arrangements for the bib ligands. From a topological point of view, each $\mathrm{Zn}$ (II) ion can be considered as a three-connected node. The 3D framework of 3 can be abstracted into a $10^{3}$-ths network topology (Fig. 3c). Moreover, three identical $10^{3}$-ths networks are interlocked with each other, forming a 3-fold interpenetrated 3D architecture (Fig. 3d). The adjacent 3D networks are interconnected by weak intermolecular $\mathrm{C}-\mathrm{H} \cdots \mathrm{O}$ hydrogen bonds, formed between oxygen atoms of the perchlorate anions and the hydrogen atoms of imidazolyl rings of the $\mu$-bib ligands (Fig. S1) [22]. In addition, significant imidazole ring stacking interactions occur in 3 (Fig. S2). The conformations of the blue colored bib ligands are such as to bring one ring of each ligand into close proximity and approximately parallel, with a centroid $\cdots$ centroid distance of $3.99 \AA$, an interplanar distance (defined as the perpendicular distance between one ring centroid and the mean plane of the other ring) of $3.35 \AA$ and a dihedral angle of $1.81^{\circ}$ between the two rings [23, 22b].

The packing of the 3D nets of $\mathbf{3}$ in the crystal structure leaves small voids, which are occupied by $\mathrm{Et}_{2} \mathrm{O}$ and water guest molecules. The calculated guest free void is about $11 \%$ of the cell volume. Position of $\mathrm{Et}_{2} \mathrm{O}$ guest molecules and perchlorate counteranions in the crystal structure is shown in Fig. S3.

\section{2. 4. Crystal structure of $\left\{\left[\mathrm{Zn}(\mu-b m i b)_{2}\right]\left(\mathrm{ClO}_{4}\right)_{2} \cdot\left(\mathrm{H}_{2} \mathrm{O}\right)_{4}\right\}_{n}(4)$}

Complex 4 crystallizes in the tetragonal space group $I 4_{1} /$ acd and has the same metal/ligand ratio and the same coordination environment as in $\mathbf{3}$. The asymmetric unit of $\mathbf{4}$ contains one $\mathrm{Zn}(\mathrm{II})$ ion, half $\mu$-bbd ligand and $\mathrm{ClO}_{4}{ }^{-}$on a 2-fold axis, together with a guest water molecule. In this complex, each $\mathrm{Zn}(\mathrm{II})$ ion is coordinated by four imidazole nitrogen atoms from four crystallographically equivalent $\mu$-bmib ligands to give a tetrahedral $\mathrm{ZnN}_{4}$ coordination geometry (Fig. 4a). The Zn-N bond distance is 1.989(4) $\AA$ and the N-Zn-N coordination angles are $97.7(2)$ and $115.7(1)^{\circ}$ (Table 3 ). These values are different from those observed in complex 3. It is likely that this observation is a consequence of the larger size and steric hindrance of the $\mu$-bmib ligands in $\mathbf{4}$. In contrast to $\mathbf{3}$, in complex 4 neighboring $\mathrm{Zn}$ (II) ions 
are interconnected by a double-bridging $\mu$-bmib ligands to form an infinite $1 \mathrm{D}$ polymeric double chain along the $c$ axis containing a centrosymmetricdinuclear 22-membered $\left[\mathrm{Zn}_{2}(\mathrm{bmib})_{2}\right]$ metallacyclic units of $\mathrm{C}, \mathrm{N}$ and $\mathrm{Zn}$ atoms. The dimeric units are arranged nearly perpendicularly to each other to reduce the steric hindrance between the methyl groups of the imidazole rings (Fig. 4b).
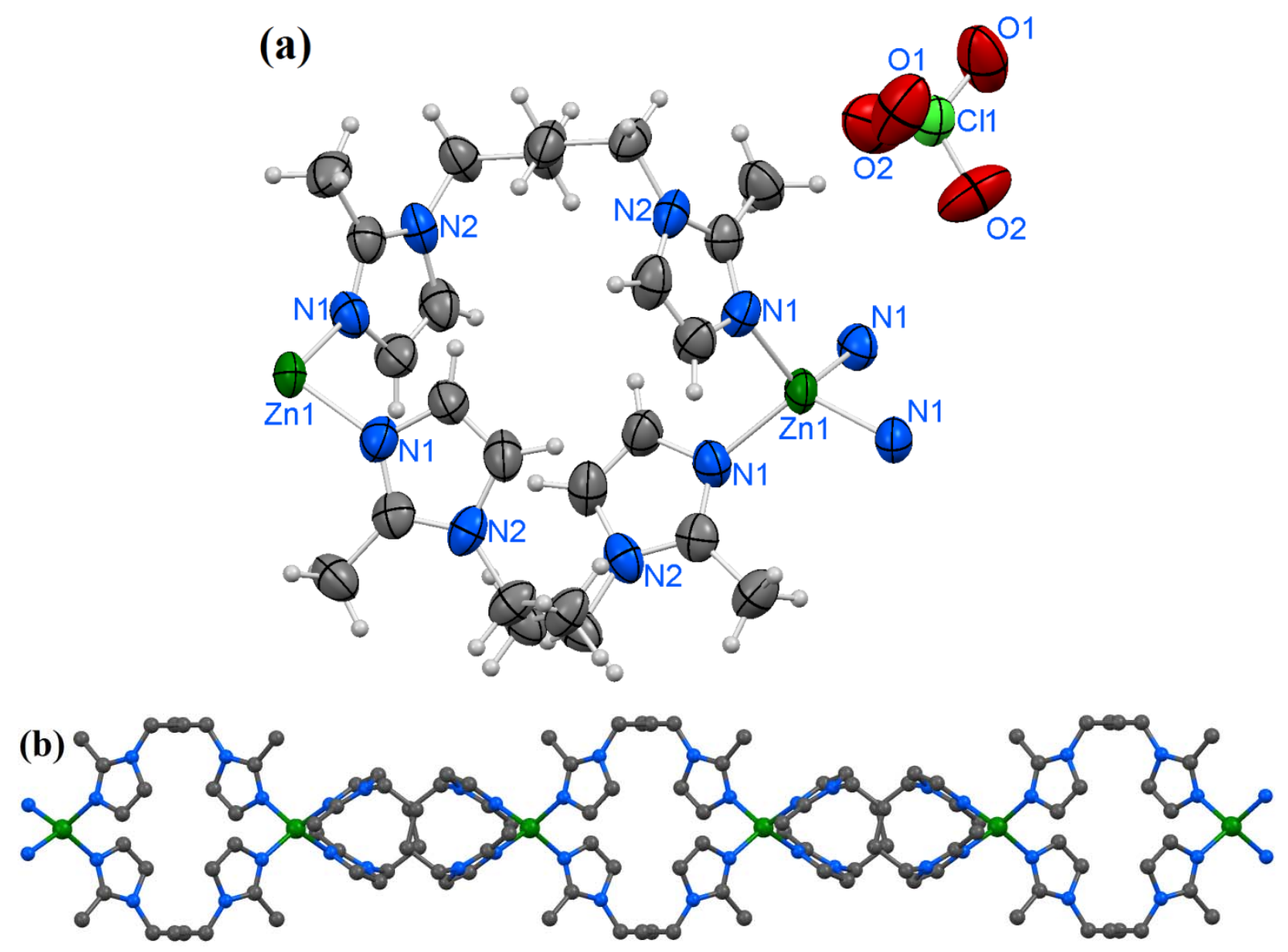

Fig. 4. (a) Coordination environment of $\mathrm{Zn}$ (II) in 4 with a labeling scheme for the asymmetric unit without disordered guest molecules. (b) Part of the cationic 1D double chain with alternating perpendicular 22membered macrometallacyclicunits .All $\mathrm{H}$ atoms in (a) and (b) have been omitted for clarity.

The adjacent $\mathrm{Zn} \cdots \mathrm{Zn}$ distance in $\mathbf{4}$ is $8.99 \AA$, which is shorter than those observed in $\mathbf{3}$ (10.30 and $11.15 \AA)$ and even in the homologue structure $\left\{\left[\mathrm{Zn}(\mathrm{bib})_{2}\right]\left(\mathrm{ClO}_{4}\right)_{2}\right\}_{\mathrm{n}}(10.85 \AA)[11 \mathrm{~d}]$. The difference between the $\mathrm{Zn} \cdots \mathrm{Zn}$ separations in these compounds can be attributed to the fact that, although the bib and bmib bridging bidentate ligands have the same spacer groups and $g a g(g ')$ conformations for the saturated NCCCCN chains, their dihedral and torsion angles are quite different from each other (Table 4).In the structure of $\mathbf{4}$, the $\mu$-bmib ligands display an eclipsed conformation with $\mathrm{N}$ to $\mathrm{N}$ distances of $6.63 \AA$, which is the shortest observed in a CSD search for the bmib ligand [24]. The 1D cationic chains are arranged parallel to each 
other running along the tetragonal $c$ direction with the perchlorate counterions located between the chains. Although, at the first glance the structure of $\mathbf{4}$ looks much similar to that of $\left\{\left[\mathrm{Zn}(\mathrm{bib})_{2}\right]\left(\mathrm{ClO}_{4}\right)_{2}\right\}_{\mathrm{n}}[11 \mathrm{~d}]$, the X-ray analyses show that there are differences in the crystal packing of these compounds that can be attributed to the methyl group of the $\mu$-bmib ligands. In contrast to the structure of $\left\{\left[\mathrm{Zn}(\mathrm{bib})_{2}\right]\left(\mathrm{ClO}_{4}\right)_{2}\right\}_{\mathrm{n}}[11 \mathrm{~d}]$ in which there is no interaction between the adjacent 1D chains, in the structure of $\mathbf{4}$, the neighboring chains extend to a single 3D supramolecular network by the $\mathrm{C}-\mathrm{H} \cdots \mathrm{O}$ hydrogen bonds formed between the oxygen atoms of the perchlorate anions as a tetrahedral 4-connected node and an hydrogen atom of imidazole rings and methyl substituents with $\mathrm{H} \cdots \mathrm{O}$ distaces of 2.45 and $2.31 \AA$, respectively (Fig. S4) [22].

The parallel square packing of the $1 \mathrm{D}$ chains leave narrow channels along the $c$ axis, containing disordered water guest molecules. The total void value of the channels without water guests is estimated (by Platon) [25] to be $460 \AA^{3}$, approximately $7.1 \%$ of the unit cell volume.

Table 4. Conformation, torsion, dihedral angles $\left({ }^{\circ}\right)$, N-to- $\mathrm{N}$ and $\mathrm{Zn} \cdots \mathrm{Zn}$ separation $(\AA)$ for the linker ligands in the structures of 1-4 and $\left\{\left[\mathrm{Zn}(\mathrm{bib})_{2}\right]\left(\mathrm{ClO}_{4}\right)_{2}\right\}_{n}[11 \mathrm{~d}]$.

\begin{tabular}{|c|c|c|c|c|c|c|c|}
\hline Compound & 1 & 2 (red) & 2 (blue) & 3 (blue)* $^{*}$ & 3 (red) & 4 & $\left\{\left[\mathrm{Zn}(\mathrm{bib})_{2}\right]\left(\mathrm{ClO}_{4}\right)_{2}\right\}_{\mathrm{n}}$ \\
\hline Conformation & $g a g^{\prime}$ & $g^{\prime a g}$ & $a a a$ & $g^{\prime a g}$ & gag & gag & eae $\dagger$ \\
\hline $\mathrm{NCCC}$ & 46.2 & -64.0 & -172.7 & $57.8 / 46.1$ & 57.4 & 65.5 & 0.0 \\
\hline $\mathrm{CCCC}$ & 180 & 180.0 & 177.2 & $159.1 / 180.0$ & 168.1 & 180 & -168.0 \\
\hline $\mathrm{CCCN}$ & -46.2 & 61.2 & 176.6 & $-72.1 /-70.3$ & 55.6 & 65.45 & 0.0 \\
\hline Dihedral angle & 0 & 3.2 & 3.7 & 1.9 & 12.4 & 17.2 & 11.0 \\
\hline N-to-N & 6.33 & 6.48 & 7.54 & 8.06 & 7.69 & 6.63 & 8.45 \\
\hline $\mathrm{Zn} \cdots \mathrm{Zn}$ & 7.74 & 7.55 & 8.08 & 10.30 & 11.15 & 8.99 & 10.85 \\
\hline
\end{tabular}

$*$ the ligand is disordered 50\%:50\%. $\dagger e=$ eclipsed

\section{3. Thermal analyses}

The thermal behaviours of compounds 1-4 were studied by TGA. A plateau in the temperature range of $50-300^{\circ} \mathrm{C}$ indicates that the molecular architecture of $\mathbf{1}$ is stable up to $300^{\circ} \mathrm{C}$ (Fig. S5). The structure of 1 begins to collapse at about $310^{\circ} \mathrm{C}$. The first total weight loss of $20.6 \%$ observed in the temperature range of $310-370^{\circ} \mathrm{C}$ corresponds to the dissociation of $\mu$-bbd ligands (calcd. 21.7\%) and decomposition of 1D chain structure. Decomposition of the remaining parts takes place on further heating and the final weight at $800^{\circ} \mathrm{C}$ is zero. The nearly complete weight loss of compounds $\mathbf{1}$ may come from the sublimation of the $\mathrm{ZnI}_{2}$ component. This phenomenon was previously observed for similar cadmium and zinc coordination polymers [26]. Compound 2 is stable up to $210^{\circ} \mathrm{C}$; the dissociation of organic 
components and architectural destruction occurs in several stages at higher temperatures. The remaining weight corresponds to the $\mathrm{Zn}(\mathrm{NCS})_{2}$ as a final residue (obsd $41.6 \%$, calcd $40.9 \%$ ). In the TGA curve of 3 , the water and $\mathrm{Et}_{2} \mathrm{O}$ guest molecules depart from the structure in the temperature range of $50-200^{\circ} \mathrm{C}$ in two steps (obsd $7.0 \%$, calcd $6.7 \%$ ). Free of guests 3D architecture of 3 is stable up to $335^{\circ} \mathrm{C}$ and the structure begins to collapse at about $345^{\circ} \mathrm{C}$. The weight loss of $57.3 \%$ in the range of $345-600^{\circ} \mathrm{C}$ is consistent with the dissociation of $\mu$ bib ligands (calcd. 57.3\%). As in 3, the first weight loss in the TGA curve of $\mathbf{4}$ corresponds to the departure of water guest molecules from the structure in the temperature range of 50$300^{\circ} \mathrm{C}$. Free of guests structure of 4 is stable up to $320^{\circ} \mathrm{C}$ and begins to collapse at about $330^{\circ} \mathrm{C}$. Pyrolysis of the organic ligand and decomposition occurs in several stages at higher temperatures.

\section{Conclusions}

In conclusion, herein we report four new zinc 1D or 3D coordination polymers by facile onepot reactions at room temperature. Complexes 1 and 2have been synthesized with the same ligand and different counteranions while complexes $\mathbf{3}$ and $\mathbf{4}$ have the same counter anions but different ligands. It was observed that the counter anions and the steric hindrance at the metal centers have significant influence on the structural topology of the complexes. Compounds $\mathbf{1}$, 2 and 4 consist of 1D polymeric chain, while $\mathbf{3}$ has 3D network structure. This observation is related to the greater steric hindrance at the metal centers in complexes $\mathbf{1}$ and $\mathbf{2}$ as compared with 3 and 4 . With decreasing the steric hindrance on the coordinating groups of the flexible ligands, we obtained more complex structures. As a result, the bbd ligand with two methyl substituents formed 1D chain structures while bmib with a methyl substituent formed 1D double chains and the bib ligand without steric hindrance around the nitrogen donor atoms, generated a 3 -fold 3D network with $10^{3}$-ths topology.

\section{Acknowledgements}

The authors thank Shahid Chamran and the UniversitàdegliStudi di Milano for financial support. DMP acknowledges the Ministry of Education and Science of Russia (Grant 14.B25.31.0005).

\section{References}

[1] (a) H. Furukawa, K.E. Cordova, M. O'Keeffe, O.M. Yaghi, Science 341 (2013) 974;

(b) T.R. Cook, Y.R. Zheng, P.J. Stang, Chem. Rev. 113 (2013) 734;

(c) C.B. Aakeroy, N.R. Champness, C. Janiak, CrystEngComm 12 (2012) 22; 
(d) S.R. Batten, N.R. Champness, X.M. Chen, J. Garcia-Martinez, S. Kitagawa, L. Öhrström, M. O'Keeffe, M.P. Suh, J. Reedijk, Pure Appl. Chem. 85 (2013) 1715.

[2] (a) J.R. Li, J. Sculley, H.C. Zhou, Chem. Rev. 12 (2012) 869;

(b) C.Y. Lee, Y.S. Bae, N.C. Jeong, O.K. Farha, A.A. Sarjeant, C.L. Stern, P. Nickias, R.Q. Snurr, J.T. Hupp, S.T.J. Nguyen, J. Am. Chem. Soc. 133 (2011) 5228.

[3] (a) M.P. Suh, H.J. Park, T.K. Prasad, D.W. Lim, Chem. Rev. 112 (2012) 782;

(b) R.B. Getman, Y.S. Bae, C.E. Wilmer, R.Q. Snurr, Chem. Rev. 112 (2012) 703.

[4] K.S. Min, M.P. Suh, J. Am. Chem. Soc. 112 (2012) 6834.

[5] M. Kurmoo, Chem. Soc. Rev. 38 (2009) 1353.

[6] Y. Cui, Y. Yue, G. Qian, B. Chen, Chem. Rev. 112 (2012) 1126.

[7] L.E. Kreno, K. Leong, O.K. Farha, M. Allendorf, R.P. Van Duyne, J.T. Hupp, Chem. Rev. 112 (2012) 1105.

[8] P. Horcajada, R. Gref, T. Baati, P. K. Allan, G. Maurin, P. Couvreur, G. Ferey, R.E. Morris, C. Serre, Chem. Rev. 112 (2012) 1232.

[9] (a) P. Horcajada, R. Gref, T. Baati, P.K. Allan,| G. Maurin, P. Couvreur, G. Ferey, R.E. Morris, C. Serre, Chem. Rev. 112 (2012) 1232;

(b) A. Corma, H. Garcia, F.X. Llabres i Xamena, Chem. Rev. 110 (2010) 4606.

[10] (a) A. Beheshti, W. Clegg, V. Nobakht, R.W. Harrington, Cryst. Growth Des.13 (2013) 1023;

(b) A. Beheshti, V. Nobakht, L. Carlucci, D.M. Proserpio, C. Abrahams, J. Mol. Struc.1037 (2013) 236;

(c) A. Beheshti, A. lalegani, G. Bruno, H.A. Rudbari, J. Mol. Struc. 1051 (2013) 244;

(d) A. Beheshti, A. lalegani, G. Bruno, H.A. Rudbari, V. Nobakht, Inorg.Chim. Acta 408 (2013) 214;

(e) A. Beheshti, Z. Beygi, C.T. Abrahams, G. Bruno, H.A. Rudbari, Polyhedron 63 (2013) 68;

(f) M.Yoon, R. Srirambalaji, K. Kim, Chem. Rev. 112 (2012) 1196;

(g) A. Beheshti, A. lalegani, G. Bruno, H.A. Rudbari, Polyhedron, 68 (2014) 372;

(h) Y.Q. Huang, X.Q. Zhao, W. Shi, W.Y. Liu, Z.L. Chen, P. Cheng, D.Z. Liao, S.P. Yan, Cryst. Growth Des. 8 (2008) 3652.

[11] (a) F.H. Zhao, Y.X. Che, J.M. Zheng, Inorg. Chem. Commun. 17 (2012) 99;

(b) W. Jing, Z.G. Ren, M.Dai, Y.Chen, J.P. Lang, CrystEngComm 13 (2011) 5111;

(c) C. Li, D.S. Li, J. Zhao, Y.Q. Mou, K. Zou, S.Z. Xiao, M.Du, CrystEngComm 13 (2011) 6601;

(d) G.H. Cui, J.R. Li, J.L. Tian, X.H. Bu, S.R. Batten, Cryst. Growth Des. 5 (2005) 1775;

(e) Y. Qi, Y. Che, F. Luo, S.R. Batten, Y. Liu, J. Zheng, Cryst. Growth Des. 8 (2008) 1654;

(f) J.F. Ma, J.F. Liu, Y. Xing, H.Q. Jia, Y.H. Lin, Dalton Trans. (2000) 2403;

(g) Y. Liu, Y. Qi, Y.Y. Lv, Y.X. Che, J.M. Zheng, Cryst. Growth Des.9 (2009) 4797;

(h) B.X. Dong, J. Peng, C.J. G. Garcia, S. Benmansour, H.Q. Jia, N.H. Hu, Inorg. Chem. 46 (2007) 5933;

(i) B.Y. Zhu, X.L. Zhang, F. Guo, X.H. Liu, Inorg. Chim. Acta 391 (2012) 58;

(j) Y.Y. Liu, Z.H. Wang, J. Yang, B. Liu, Y.Y. Liu, J.F. Ma, CrystEngComm 13 (2011) 3811.

[12] (a) Y.J. Huang, Y.L. Song, Y. Chen, H.X. Li, Y. Zhang, J.P. Lang, Dalton Trans. (2009) 1411;

(b) L.L. Li, L.L. Liu, A.X. Zheng, Y.J. Chang, M. Dai, Z.G. Ren, H.X. Li, J.P. Lang, Dalton Trans. 39 (2010) 7659.

[13] H. Ohtsu, Y. Shimazaki, A. Odani, O. Yamauchi, W. Mori, S. Itoh, S. Fukuzumi, J. Am. Chem. Soc. $122(2000) 5733$. 
[14] S.L. Li, Y.Q. Lan, J.F. Ma, J. Yang, G.H. Wei, L.P. Zhang, Z.M. Su, Cryst. Growth Des.8 (2008) 675.

[15] G.M. Sheldrick, SHELX97-Programs for Crystal Structure Analysis, release 97-2; Institut fur AnorganischeChemie der Universitat Gottingen, Gottingen, Germany (1998).

[16] N. Sundaraganesan, E. Kavitha, S. Sebastian, J.P. Cornard, M. Martel, Spectrochim. Acta 74A (2009) 788

[17] Y. Feng, N. Liang, B. Li, H. Li, Acta Cryst. E66 (2010) m560.

[18] L.M. Richburg, J.A. Farouq, C.D. Incarvito, A.L. Rheingold, D. Rabinovich, Polyhedron 19 (2000) 1815.

[19] U. Arnold, O. Walter, M. Doring, Inorg. Chim.Acta 359 (2006) 327.

[20] (a) V. Balamurugan, R. Mukherjee, CrystEngComm, 7 (2005) 337;

(b) J. Ehrhart, J.M. Planeix, N.K. Gruber, M.W. Hosseini, Dalton Trans. 39 (2010) 2137;

(c) C.T. Chen, W.K. Chang, S.C. Sheu, G.H. Lee, T.I. Ho, Y.C. Lin, Y. Wang, J. Chem. Soc., Dalton Trans. (1991) 1569;

(d) X. Wang, J.S. Gao, Z.Y. Ding, G F. Hou, ActaCrystallogr., Sect. E: Struct. Rep. Online, 66 (2010) m700;

(e) M. Guerrero, J. Pons, T. Parella, M. Font-Bardia, J. Ros, Inorg. Chem. 48 (2009) 8736;

(f) W.G. Haanstra, W.L. Driessen, J. Reedijk, U. Turpeinen, R. Hamalainen, J. Chem. Soc., Dalton Trans. (1989) 2309.

[21] (a) B. Bovio, A. Cingolani, F. Bonati, Z. Anorg. Allg. Chem. 610 (1992) 151;

(b) D.A. McMorran, S. Pfadenhauer, P.J. Steel, Aust. J. Chem. 55 (2002) 519;

(c) A.M. Schuitema, M. Engelen, I.A. Koval, S. Gorter, W.L. Driessen, J. Reedijk, Inorg. Chim. Acta 324(2001) 57;

(d) B. Bovio, A. Cingolani, C. Pettinari, G.G. Lobbia, F. Bonati, Z. Anorg. Allg. Chem. 602 (1991) 169;

(e) J.L. Shaw, K.P. Gwaltney, N. Keer, Inorg. Chim.Acta362 (2009) 2396;

(f) A.S. Potapov, E.A. Nudnova, A.I. Khlebnikov, V.D. Ogorodnikov, T.V. Petrenko, J. Heterocycl. Chem. 48 (2011) 645;

(g) C. Pettinari, A. Cingolani, B. Bovio, Polyhedron 15 (1996) 115.

[22] (a) J.L. Atwood, J.W. Steed, Encyclopedia of Supramolecular Chemistry, CRC Press, Boca Raton(2004);

(b) L. Carlucci, G. Ciani, S. Maggini, D.M. Proserpio, CrystEngComm 10 (2008) 1191;

(c) E. Arunan, G.R. Desiraju, R. A. Klein, J. Sadlej, S. Scheiner, I. Alkorta, D.C. Clary, R.H. Crabtree, J.J. Dannenberg, P. Hobza, H.G. Kjaergaard, A.C. Legon, B. Mennucci, D.J. Nesbitt, J. Pure Appl. Chem. 83 (2011) 1637;

(d) A. Frontera, Coord. Chem. Rev. 257 (2013) 1716;

(e)S. Brooker, N.G. White, A. Bauzá, P.M. Deyà, A.Frontera, Inorg. Chem. 51 (2012) 10334;

(f) N.G. White, J.A. Kitchen, S. Brooker, Eur. J. Inorg. Chem. (2009) 1172;

[23] C. Janiak, J. Chem. Soc., Dalton Trans. (2000) 3885.

[24] Cambridge Structural Database (CSD, version 5.33 with 4 updates, May 2012), F. H. Allen, ActaCrystallogr., Sect. B: Struct. Sci. 58 (2002) 380.

[25] A.L. Spek, J. Appl. Crystallogr. 36 (2003) 7.

[26] (a) Q.G. Zhai, X.Y. Wu, S.M. Chen, C.Z. Lu, W.B. Yang, Cryst. Growth Des.6 (2006) 2126;

(b) M. De F.V. De Moura, O.A. De Oliveria, R.F. De Farias, Thermochim. Acta, 405 (2003) 219;

(c) R.B. Zhang, Z.J. Li, J.K. Cheng, Y.Y. Qin, J. Zhang, Y.G. Yao, Cryst. Growth Des.8 (2008) 2562; 
(d) P. Cui, Z. Chen, D. Gao, B. Zhao, W. Shi, P. Cheng, Cryst. Growth Des. 10 (2010) 4370. 